\title{
Malnutrition Among Children Under Five Years in Uganda
}

\author{
Ratib Mawa, Stephen Lawoko* \\ Department of Public Health, Faculty of Health Sciences, Victoria University, Kampala, Uganda \\ Email address: \\ mawaratib2016@gmail.com (R. Mawa), deanhealthscience@vu.ac.ug (S. Lawoko) \\ ${ }^{*}$ Corresponding author
}

\section{To cite this article:}

Ratib Mawa, Stephen Lawoko. Malnutrition Among Children Under Five Years in Uganda. American Journal of Health Research. Vol. 6, No. 2, 2018, pp. 56-66. doi: 10.11648/j.ajhr.20180602.14

Received: April 6, 2018; Accepted: April 28, 2018; Published: May 24, 2018

\begin{abstract}
Malnutrition remains a major cause of morbidity and mortality among children under five years especially in developing countries. The high burden of wasting and stunting among children under five years of age is of great concern to policy makers and public health practitioners in Uganda. Prevention and treatment of malnutrition is a priority in the United Nations 2030 development agenda. This study investigated the risk factors for wasting and stunting among children aged 6-59 months in the general population in Uganda. Secondary data from the 2011 Uganda Demographic and Health Survey was utilised. A sample of 2214 children was studied. Bivariate analysis and multivariate conditional logistic regression was used to determine the association between risk factors and childhood wasting and stunting. 5\% and 33.5\% of the children were wasted and stunted respectively. Risk factors associated with wasting were lack of maternal education; OR (3.66; 1.22-11.01), maternal underweight -BMI $<18.5 \mathrm{~kg} / \mathrm{m}^{2}$; OR $(3.39 ; 1.72-6.70)$ and children aged $6-11$ months OR (2.20; $\left.1.09-4.42\right)$. On the other hand, those risk factors associated with stunting included: child's very small size at birth; OR (2.59; 1.58-4.27), male children; OR (1.5; 1.12 -2.18), children aged 24-35 months (1.17-3.23), maternal height $<150 \mathrm{~cm}$; OR (7.53; 4.07-13.94) and lack of maternal education; OR $(2.47 ; 1.37-4.44)$. In conclusion, children's age and low maternal formal education level predicts wasting. Likewise, children`s male gender, age, size at birth, maternal height and low maternal formal education level also predicts stunting among children under five years of age. This finding suggests that interventions to reduce under-five stunting and wasting in Uganda may benefit from focusing on improvement of maternal nutritional status and formal education.
\end{abstract}

Keywords: Malnutrition, Wasting, Stunting, Prevalence, Risk Factors, Children Under Five, Uganda

\section{Introduction}

Malnutrition remains a major global public health challenge, especially among children under five years of age [1]. Its impact on child survival [2] and future national economic productivity [3] cannot be over-emphasized. Recent global estimates suggested a declining trend in the global prevalence of stunting and wasting (types of undernutrition) among children less than five years. Africa among other United Nation regions registered the lowest percentage decrease in prevalence of stunting (18\%) from 2000 - 2016. In most sub-Saharan African countries, the level of wasting among children under-five years of age remained below emergency threshold level but at poor nutritional threshold levels (6.5\%) for East Africa [4]. Black and colleagues showed that approximately $45 \%$ of all deaths in children under five years were associated with malnutrition [6]. This further underpins the impact of malnutrition on child survival.

The 2011 Uganda Demographic and health survey (UDHS) showed a wasting and stunting prevalence of 5\% and $33 \%$ respectively among children under five years of age [7]. Rural children were more disproportionately affected than their urban counterparts. In addition, the economic costs associated with childhood malnutrition in Uganda are of serious concern to policy makers, public health professionals and public health researchers. A burgeoning annual economic loss of 1.8 trillion Ugandan shillings (US\$899 million), an equivalent of $6 \%$ of the country`s Gross Domestic Product was reported [8]. This economic haemorrhage, malnutrition related premature childhood deaths [9] and its sequel in a life-course perspective [10-12] are very important negative 
signals for Uganda's development. To reduce the burden of wasting and stunting among children under five years, globally applicable evidence based nutrition specific and sensitive interventions were recommended [13], however the success of these interventions depends on several factors among which include identification of local and country specific malnutrition risk factors, the benchmark for nutrition policy and interventions development, advocacy for resource envelop and political commitment. [14, 15].

Three major types of undernutrition are explicit; stunting, wasting and underweight. Stunting is a chronic form of undernutrition which reflects prolonged period of insufficient nutrient intake and assimilation. It's also an indicator of overall societal socio-economic conditions [16]. Wasting on the other hand is an acute form of undernutrition, an indicator of body tissue and fat mass deficit resulting from insufficient nutrient intake within a short-period of time. It's often used as an educated guess of the general population health [16, 17]. A child is considered to be either stunted or wasted if his/her length/height-for-age and weight-for-height z-scores is $<-2$ standard deviation of the WHO Child Growth Standards median respectively [18]. Lastly underweight, a third sub-division of undernutrition is a composite measure that includes both wasting and stunting. It accounts for $95 \%$ of the variance in weight-for-height index [19], however has less discriminatory power for undernutrition and less utilised for that purpose.

Risk factors for wasting and stunting are overt across the globe. In the Lancet series of maternal and child nutrition, two systematic reviews by Black et al delineated the potential risk factors for wasting and stunting among children under five years of age at both global and regional level [2], in middle and low-income countries [6], let alone the comprehensive UNICEF framework of determinants of malnutrition. Risk factors for stunting rang from societal level factors such as political context and socio-economic status to individual level factors such as inadequate dietary intake and infections. Low socio-economic status is an important distal risk factor for stunting. In particular limited maternal opportunity to earn and limited health knowledge resulting from lack of or limited formal education as opposed to paternal education, aggravates other correlates of stunting such as poor child-care practices related to nutrition, health and access to existing nutrition and health interventions. Maternal short stature and low maternal body mass index $\left(<18.5 \mathrm{~kg} / \mathrm{m}^{2}\right)$ have synergistic effect on pregnancy outcomes with the earlier leading to increased probability of operative delivery and the later intrauterine growth restriction thought to be the beginning point of linear growth faltering and a precursor for neonatal conditions. Maternal undernutrition also affects micronutrient quantity (cobalamine, vitamin A, thiamine, riboflavin, iodine, thiamine and pyridoxine) in breast milk resulting into insufficient supply to exclusively breastfed children [20].The immediate risk factors for stunting in developing countries as alluded to earlier on are; inadequate dietary intake and frequent infections such as diarrhoeal diseases, measles, malaria, pneumonia and meningitis which interact in a process known as the malnutrition-infection cycle. Risk factors for wasting are synonymous with those for stunting though a slight difference exists.

The above findings corroborate the UNICEF conceptual framework of malnutrition that illustrated the hierarchical multi-causal pathways for malnutrition [21].This framework aligns with the new WHO causal framework for stunting [22]. The former conceptual framework demarcated causes of undernutrition into three levels; the immediate causes at individual level, of which include repeated infections and inadequate dietary intake. The underlying causes at household level; inadequate access to food, poor maternal and child care practices, inadequate access to healthcare services and unhealthy living environment. These underlying causes are in-turn influenced by basic factors which operate at societal level among which include; national resource control, political and ideological orientations, economic structure, the political economy and national resource potential of the country. The WHO framework on causes of stunting grouped the risk factors into two levels; factors operating at household level and those operating at community and societal level (contextual factors) [22].

Limited number of studies reported the known and or persisting risk factors for undernutrition among children under five years in Uganda. The few available studies reported episodes of fever [23], lack of breast feeding, poor dietary diversity, incomplete vaccination status and proxy measures of socio-economic status such as lack of land for farming, residing in a mud walled house and lack of livestock in the household, lack of paternal and maternal education $[24,25]$ as potential predictors of wasting among children under five years of age in Uganda. Other potential risk factors for wasting were maternal occupation (farmer or pastoralist), maternal age $\geq 40$ years and $<30$ years, children in the birth order of $\geq 3$ and being a female child [26].

For stunting, the reported risk factors include; episode of fever, lack of de-worming, not having received milk in the last 24hours, lack of access to latrine, low maternal formal education, child being a male, children in the birth order of $\geq 3$, maternal age 30-39years, married/cohabiting mothers compared to single mothers, mothers occupation as a business/civil/handcraft maker compared to peasant farmers $[23,26]$. Although there is commonality in reported risk factors for stunting and wasting, some of these studies were less powered as sample sizes where questionable and others used operational definitions of stunting and wasting with erroneous cut-offs [24, 26] hence increased probability of type 1 error, misclassification of the outcomes with respect to the exposures and residual confounding cannot be ruled out. In addition, these studies were conducted only in the central and western regions of the country with one in a hospital setting [25], this limits the potential for generalisation of the results to all children under five years in country. Understanding persisting risk factors for wasting and stunting and the at-risk groups at national level is essential to inform nutrition interventions and policy development at national 
level. This paper investigated the persisting risk factors for wasting and stunting among children under five years of age in the general population in Uganda.

\section{Methods}

\subsection{Data Source, Study Design and Setting}

Data from the 2011 Uganda Demographic and Health Survey (UDHS) was used for this study. It was accessed after a written permission from the Demographic and Health Survey Program [27]. The UDHS is a five-year interval national survey sponsored by USAID. It provides the only source of nationally representative data on child anthropometry and malnutrition. The 2011 UDHS was a cross-sectional study in which a sample of 10,086 households were selected across 10 regions using a stratified two-stage cluster sampling design based on the sampling frame for the 2002 Uganda population census [28]. The household response rate was $95.3 \%$. Within households, the target populations were married and unmarried women aged 15-49 years and children aged 6-59 months. All men aged 15-54 were also interviewed. In each household, women who met the inclusion criteria were interviewed using standard DHS questionnaire adopted to fit country specific data needs [7]. The 2011 UDHS had a total of 9,247 eligible women in selected households interviewed. The women response rate was $93.8 \%$. Similarly, for men, a total of 2,573 were selected with a participant response rate of $89.2 \%$. All children under five years in the selected households had their anthropometric measurements taken. Readers may refer to the 2011 UDHS report [7] for detailed description of the sampling design and sample selection procedures. This was therefore a cross sectional study that investigated risk factors for stunting and wasting among children under five years living in households located in both rural and urban areas of Uganda.

\subsection{Study Population}

The study population was children aged 6-59 months at the time of anthropometric measurement in 2011. Selection of this age group was based on prior knowledge of at-high risk group and evidence on nutrition interventions that works [13, 29]. A total of 7878 children were registered in the selected households during the survey. In the dataset, we excluded $523(6.64 \%)$ deceased children, $5141(65.26 \%)$ for not having met the criteria for anthropometric measurements. A total of 2214 children with data on anthropometry were selected for the analysis. However we further excluded 40 $(1.8 \%)$ children with implausible height and weight measurements (flagged cases) [30] and 104 (4.7\%) who had either weight or height measurements missing, leaving a total of 2070 with complete and plausible weight and height measurement for the final analysis.

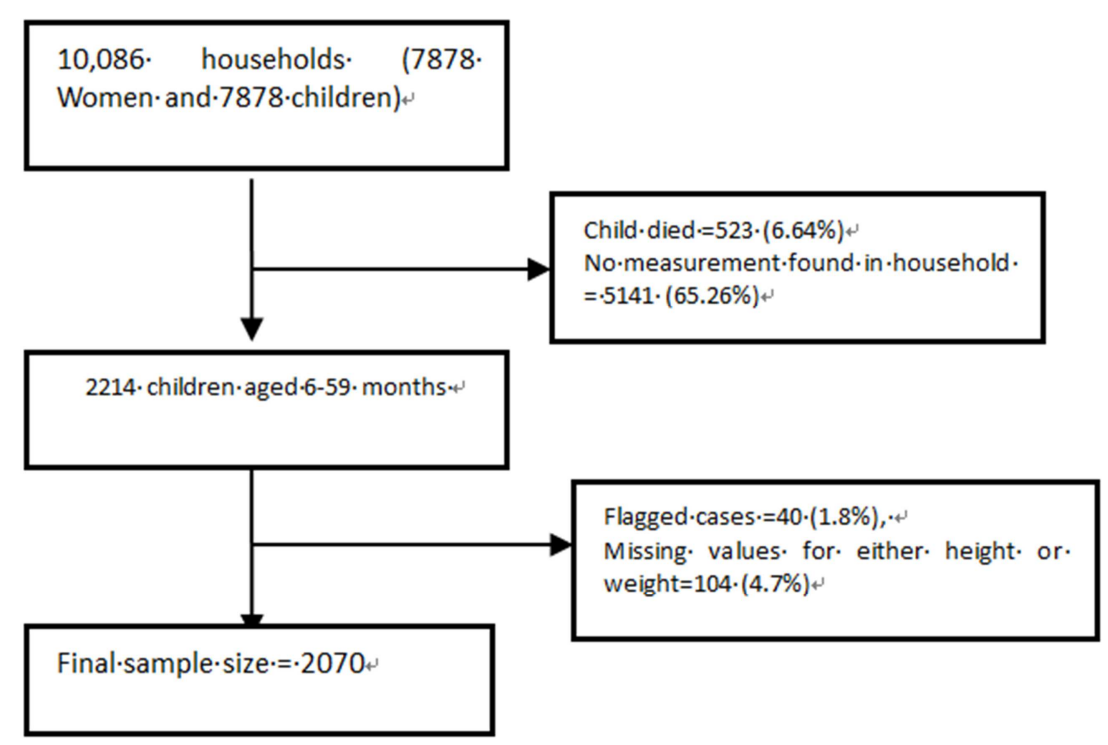

Figure 1. Schematic illustration of the exclusion criteria and final sample sizes for this study.

\subsection{Assessment of Wasting and Stunting}

Globally anthropometric measurements are the most widely accepted and applied diagnostic procedure for stunting and wasting among children under five years [31]. In the 2011 UDHS, children's height/length and weight measurements were conducted by two trained survey enumerators in each survey team [7]. Weight was measured and recorded to the nearest 0.1 kilogram using lightweight electronic SECA mother-infant scales. Height was measured using wooden stadiometers and recorded to the nearest $0.1 \mathrm{~cm}$ following the WHO recommended child height and weight measurement procedures [18]. Children's height were measured in standing position if they were $\geq 24$ months of age and in recumbent (lying down) position for those $<24$ months of age or unknown age and height $<85 \mathrm{~cm}$ to obtain their length [7]. The height and weight values were then used to calculate sex-specific anthropometric indices based on the new WHO growth standards [18]. Children who had weightfor-height and height/length-for-age z-scores $<-2$ standard 
deviation of the WHO Child Growth Standards median were defined as having wasting and stunting respectively [18].

\subsection{Risk Factor Assessment}

Downstream and upstream risk factors for undernutrition based on the UNICEF conceptual framework of determinants of malnutrition were included [2, 32]. In the 2011 UDHS, malnutrition risk factors were assessed using standard questionnaire, observation and anthropometric measurements. Women aged 15-49 years of age responded to structured questionnaires, administered by trained survey enumerators. The following 12 exposure variables, grouped into three main categories were selected based on prior evidence of their association with malnutrition in children under five years of age.

\subsubsection{Children's demographic characteristics}

Children's demographic characteristics were provided for in the DHS dataset, variables were used without much modification. Child's gender; Women were asked about their children's sex and responses were then recorded as male 2 and female 1. Child's age was assessed by asking women for the child's date of birth and verification by either birth certificate or immunisation card where applicable. The exact ages in months were then calculated by subtracting the recoded date of birth from the interview date. Children's age in months were then categorised into five age groups; $6-11$, 12-23, 24-35, 36-47 and 48-59 months and utilised as such during our analysis. Child's size at birth; was assessed by asking mothers to estimate the size of their child compared to an average size of a child at birth. Mothers responses were then recoded and grouped into five categories; very small 1, small 2, average 3, large 4 and very large 5 .

\subsubsection{Immediate Risk Factors}

Infectious disease in the last two weeks; women were also asked if their children had experienced fever, diarrhoea or cough in the last two weeks preceding the survey. Fever in children under five years is an indicator of mainly malaria and other infectious disease in high prevalence areas [33]. Responses to disease or symptom specific questions were recorded as $1=$ Yes if a child had fever, diarrhoea and cough in the last two weeks or 0 otherwise. A composite variable indicating whether a child experienced or did not experience infectious diseases in the last two weeks preceding the survey was then generated and coded as 1 if a child had experienced an infectious disease and 0 otherwise. Child's vaccination status; mothers were also asked about how many doses of BCG, DPT, Polio and measles vaccine their child/children received. Their responses were then verified by checking their children's vaccination cards. These variables were then used to create a composite bivariate variable labelled child's vaccination status, recorded as 1 if child didn't receive vaccination and 0 otherwise. Dietary diversity score; women were also asked about the foods they fed their children during the last 24 hours preceding the survey, multiple responses were recorded in the original variables. We then created a dietary diversity scores using the WHO 7 category food groups and generated quintiles of the dietary diversity score using methods employed by Barros et al [34].

\subsubsection{Underlying Factors}

Maternal formal education level was assessed by asking women for the highest level of education they had attained at the time of the survey. Their responses were then recoded into four categories; no formal education, primary, secondary, tertiary and university. However due to small number of recorded responses in the last three categories, we combined women with secondary/tertiary/university level education into one group of formal education level, even though this had the potential of misclassification. Hence, we ended up using maternal education variable with three categories of formal education level in the analysis; No education, primary and secondary/tertiary/university education levels. Maternal height; Heights of interviewed mothers were measured using measuring boards and recorded to the nearest $0.1 \mathrm{~cm}$. Women`s heights were then grouped into four categories $<150 \mathrm{~cm}, 150-154.9 \mathrm{~cm}, 155$ $159.9 \mathrm{~cm}$ and $160 \mathrm{~cm}$ and above. Maternal body mass index (BMI) was assessed by measuring maternal weight using mother-child electronic SECA scale and recorded to the nearest $0.1 \mathrm{~kg}$. Using maternal height and weight measurements, body mass index was calculated by dividing maternal weight in kilograms by her height in meter squared. Maternal BMI scores were then grouped into four categories; $<18.5 \mathrm{~kg} / \mathrm{m}^{2}, 18.5-24.99,25.0-29.99$, and 30 $\mathrm{kg} / \mathrm{m}^{2}$ and above using appropriate classification cut-off points corresponding to underweight, normal weight, overweight and obese respectively [35]. Drinking water sources; Sources of household's drinking water were determined in the DHS by asking mothers where they collected household's drinking water from. A new bivariate variable that grouped listed water sources into improved and unimproved drinking water sources based on the joint WHO/UNICEF classification of water sources [36] was created and recoded as 1 unimproved drinking water sources and 0 otherwise. Household sanitation; In the DHS, women were asked about the type of toilet facilities their households use, this question was complemented by direct observation of toilet facilities for functionality and usage. A new variable that classified households into improved and unimproved sanitation facilities was created using standard definition [36]. Household Wealth Index; Household's wealth status was assessed by asking women various questions including listing their household assets, water sources, type of sanitary facilities, type of dwelling houses and materials used for their construction. A wealth index was then created using the methodology of principle component analysis [37]. Households were then grouped into five wealth index groups ranging from the $20 \%$ poorest households to the top $20 \%$ richest households. The wealth index variable was used in the analysis as it was recorded in the DHS dataset. 


\section{Statistical Analysis}

Chi-square tests were applied to study the association between categorical risk factors and stunting / wasting at the bivariate level. At the multivariate level, two separate conditional logistic regression models were then fitted with adjusted odds ratios reflecting the strength of independent associations between risk factors and the outcomes of interest. In both models (for wasting and stunting) we mutually adjusted for all included risk factors (child's age, sex, size at birth, maternal height, maternal body mass index, maternal education level, household's drinking water sources, types of sanitary facilities, experience of infectious disease in the last two weeks preceding the survey, child's vaccination status, child's dietary diversity score and household wealth index. A statistical significance level of $\mathrm{P}<$ 0.05 was assumed. All analysis accounted for clustering and stratification introduced by the survey design. Statistical analysis was conducted using STATA v12.0.

\section{Ethical Consideration}

Permission to use the 2011 UDHS data was obtained from the Demographic and Health Survey program data management team [38]. Being a secondary data analysis, we had no interface with study participants. Data received from the DHS team had no subject specific identification details. However prior to the data collection exercise, the UDHS team followed standard ethical approval practices for conduct of studies among human subjects in Uganda. No violation of the principles of ethical conduct of studies among human subjects was reported in the 2011 UDHS report or directly by study subjects to the authorised authorities.

\section{Results}

Socio-demographic characteristics

Half $(50.1 \%)$ of the children $<5$ years of age were girls. More were in the age group of 6-11 months (23\%) and almost half (40\%) were reported to have had an average size at birth (Table1).

Table 1. Unweighted and weighted distribution of children aged 6-59 months according to risk factors, wasting and stunting in the 2011 Uganda Demographic and Health Survey $(n=2214)$.

\begin{tabular}{|c|c|c|c|c|c|c|c|c|}
\hline \multirow[b]{2}{*}{ Variables } & \multicolumn{2}{|l|}{ Total $(n=2214)$} & \multicolumn{3}{|c|}{ Wasting $(n=2070)$} & \multicolumn{3}{|c|}{ Stunting $(n=2070)$} \\
\hline & $\begin{array}{l}\text { Un-weighted } \\
\text { Number }\end{array}$ & $(\%)^{\mathrm{a}}$ & Weighted No. & $(\%)$ & P-value & $\begin{array}{l}\text { Weighted } \\
\text { No. }(\%) \\
\end{array}$ & $(\%)$ & P-value \\
\hline \multicolumn{9}{|l|}{ Sex } \\
\hline Female & 1109 & 50.09 & 1043 & 5.21 & 0.21 & 1043 & 29.50 & 0.002 \\
\hline Male & 1105 & 49.91 & 1026 & 4.78 & & 1026 & 37.50 & \\
\hline Total & 2214 & & 2069 & 5.00 & & 2069 & 33.50 & \\
\hline \multicolumn{9}{|l|}{ Age (Months) } \\
\hline $6-11$ & 513 & 23.17 & 464 & 11.20 & $<0.001$ & 464 & 16.50 & $<0.001$ \\
\hline $12-23$ & 481 & 21.73 & 470 & 5.57 & & 470 & 38.00 & \\
\hline $24-35$ & 417 & 18.83 & 387 & 2.12 & & 387 & 46.00 & \\
\hline $36-47$ & 421 & 19.02 & 397 & 1.76 & & 397 & 35.90 & \\
\hline $48-59$ & 382 & 17.25 & 352 & 2.80 & & 352 & 33.40 & \\
\hline \multicolumn{9}{|l|}{ Child's size at birth } \\
\hline Average & 859 & 39.73 & 786 & 3.64 & $<0.003$ & 786 & 31.50 & $<0.001$ \\
\hline Very Small & 124 & 5.74 & 100 & 11.80 & & 100 & 42.90 & \\
\hline Small & 365 & 16.88 & 342 & 3.42 & & 342 & 42.60 & \\
\hline Large & 642 & 29.69 & 622 & 4.59 & & 622 & 31.60 & \\
\hline Very Large & 172 & 7.96 & 164 & 3.02 & & 164 & 23.50 & \\
\hline \multicolumn{9}{|l|}{ Vaccination Status } \\
\hline Fully vaccinated & 2084 & 94.13 & 1947 & 4.74 & 0.05 & 1947 & 33.40 & 0.81 \\
\hline Not fully vaccinated & 130 & 5.87 & 122 & 9.09 & & 122 & 34.70 & \\
\hline Infectious disease last 2 weeks & & & & & & & & \\
\hline No & 759 & 34.28 & 641 & 4.48 & 0.53 & 641 & 32.40 & 0.59 \\
\hline Yes & 1455 & 65.72 & 1428 & 5.23 & & 1428 & 34.00 & \\
\hline \multicolumn{9}{|l|}{ Maternal Height (cm) } \\
\hline$<150$ & 139 & 6.35 & 142 & 4.16 & 0.49 & 142 & 59.10 & $<0.001$ \\
\hline $150-154$ & 383 & 17.49 & 380 & 3.37 & & 380 & 38.60 & \\
\hline $155-159$ & 686 & 31.32 & 642 & 5.74 & & 642 & 37.00 & \\
\hline $160 \&$ above & 982 & 44.84 & 897 & 5.18 & & 897 & 25.00 & \\
\hline \multicolumn{9}{|l|}{ Maternal BMI $\left(\mathrm{Kg} / \mathrm{m}^{2}\right)$} \\
\hline$<18.5$ & 245 & 11.22 & 195 & 13.6 & $<0.001$ & 195 & 30.40 & $<0.01$ \\
\hline $18.5-24.99$ & 1552 & 71.06 & 1517 & 4.22 & & 1517 & 36.00 & \\
\hline $25-29.99$ & 299 & 13.69 & 269 & 1.99 & & 269 & 26.60 & \\
\hline $30 \&$ above & 88 & 4.03 & 76 & 7.94 & & 76 & 17.50 & \\
\hline \multicolumn{9}{|l|}{ Maternal Education level } \\
\hline No Education & 382 & 17.25 & 257 & 7.51 & 0.24 & 257 & 40.20 & $<0.001$ \\
\hline Primary & 1326 & 59.89 & 1362 & 4.59 & & 1362 & 35.10 & \\
\hline Secondary/higher & 506 & 22.85 & 450 & 4.80 & & 450 & 24.70 & \\
\hline
\end{tabular}




\begin{tabular}{|c|c|c|c|c|c|c|c|c|}
\hline \multirow[b]{2}{*}{ Variables } & \multicolumn{2}{|c|}{ Total $(n=2214)$} & \multicolumn{3}{|c|}{ Wasting $(\mathrm{n}=2070)$} & \multicolumn{3}{|c|}{ Stunting $(\mathrm{n}=\mathbf{2 0 7 0})$} \\
\hline & $\begin{array}{l}\text { Un-weighted } \\
\text { Number }\end{array}$ & $(\%)^{a}$ & Weighted No. & $(\%)$ & P-value & $\begin{array}{l}\text { Weighted } \\
\text { No. }(\%)\end{array}$ & (\%) & P-value \\
\hline \multicolumn{9}{|l|}{ Drinking water source } \\
\hline Improved & 1642 & 75.67 & 1458 & 4.52 & \multirow[t]{3}{*}{0.26} & 1458 & 31.60 & \multirow[t]{3}{*}{0.02} \\
\hline Unimproved & 528 & 24.33 & 564 & 5.92 & & 564 & 38.30 & \\
\hline Sanitary facilities & & & & & & & & \\
\hline Improved & 1010 & 46.37 & 1000 & 4.25 & \multirow{3}{*}{0.21} & 1000 & 34.18 & \multirow[t]{3}{*}{0.68} \\
\hline Unimproved & 1168 & 53.63 & 1033 & 5.60 & & 1033 & 33.13 & \\
\hline \multicolumn{7}{|l|}{ Dietary Diversity score } & & \\
\hline Quintile 1 (Lowest) & 376 & 23.49 & 324 & 7.80 & \multirow[t]{6}{*}{0.11} & 324 & 27.80 & \multirow[t]{6}{*}{0.05} \\
\hline Quintile 2 & 438 & 27.36 & 455 & 4.83 & & 455 & 31.60 & \\
\hline Quintile 3 & 227 & 14.18 & 214 & 8.44 & & 214 & 42.40 & \\
\hline Quintile 4 & 253 & 15.80 & 241 & 5.14 & & 241 & 35.70 & \\
\hline Quintile 5 (Highest) & 307 & 19.18 & 307 & 3.29 & & 307 & 30.80 & \\
\hline \multicolumn{7}{|l|}{ Wealth Index } & & \\
\hline Poorest & 575 & 25.97 & 449 & 4.68 & \multirow[t]{5}{*}{0.29} & 449 & 36.60 & \multirow[t]{5}{*}{$<0.001$} \\
\hline Poor & 431 & 19.47 & 448 & 6.37 & & 448 & 30.50 & \\
\hline Middle & 392 & 17.71 & 420 & 6.24 & & 420 & 45.80 & \\
\hline Richer & 358 & 16.17 & 393 & 4.15 & & 393 & 30.70 & \\
\hline Richest & 458 & 20.69 & 358 & 3.14 & & 358 & 21.90 & \\
\hline
\end{tabular}

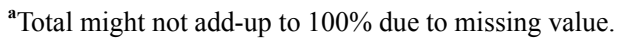

\subsection{Risk Factor Distribution}

Two-thirds of the children had experienced at least one episode of infectious disease in the last two weeks preceding the survey, $6 \%$ were not fully vaccinated and over $40 \%$ had poor access to food of diverse quality. Levels of risk factors related to maternal characteristics were prevalent in the sample. $6.5 \%$ of the mothers had height measurement of less than 150 centimetres, $11.5 \%$ with BMI $<18.5 \mathrm{~kg} / \mathrm{m}^{2}$ and three quarters of these women had either attained primary level or no formal education at all. Approximately a quarter (24\%) and $21 \%$ of the households do not have access to drinking water sources of improved quality and improved household sanitation facility respectively. Close to half (45\%) of the children lived in the poorest and poor households (Table 1).

\subsection{Prevalence of Wasting and Stunting}

The prevalence of wasting in both boys and girls was 5\%; no gender differences were observed. More cases of wasting occurred among children aged 6 -11months (11\%), among those with very small size at birth $(12 \%)$ and in children born to mothers with BMI $<18.5 \mathrm{~kg} / \mathrm{m}^{2}(14 \%)$. No differences were found in the prevalence of wasting with regards to the distribution of other risk factors. On the other hand, more cases of stunting occurred among boys (37.5\%) compared to girls (29\%) and in children aged 24-35 months (46\%), among those whose maternal height was $<150 \mathrm{~cm}(59 \%)$, maternal BMI $<18.5 \mathrm{~kg} / \mathrm{m}^{2}(30 \%)$ and BMI between $18.5 \& 24.99$ $\mathrm{kg} / \mathrm{m}^{2}(36 \%)$ and among those whose mothers had no formal education (40\%). Higher proportion of stunted children were also found in households with no access to improved drinking water sources (38\%) than those with access to improved drinking water sources $(31.6 \%)$, medium dietary diversity score (42\%) and among children whose households were classified in the middle household wealth quintile (46\%) (Table1)

\subsection{Association between risk Factors and Wasting}

Table 2 presents the odds ratios (OR) for wasting, mutually adjusted for included risk factors. Risk factors associated with wasting included: maternal body mass index - BMI $<18.5 \mathrm{~kg} / \mathrm{m}^{2}$ associated with 3 -fold increase in wasting, OR $(3.39 ; 1.72-6.70)$ in comparison with children whose mothers had normal BMI (18.5 -24.99 $\left.\mathrm{kg} / \mathrm{m}^{2}\right)$; lack of maternal formal education was associated with 3 -fold increase, OR $(3.66 ; 1.22-11.01)$ and maternal primary education level $80 \%$ increase in wasting; OR $(1.80 ; 1.73-4.44)$ in comparison with children whose mothers had secondary level education or higher. Children who were in the age range of $6-11$ months had higher risk of wasting, OR (2.20; 1.09 -4.42) compared to those aged 12-23 months. The other risk factors did not show statistically significant relationship with wasting despite of having shown high odds ratios. These included; child`s size at birth, having experienced infectious disease in the last two weeks preceding the survey, lack of full vaccination status, unimproved drinking water sources, unimproved household sanitation, dietary diversity score, maternal BMI $\geq 30 \mathrm{~kg} / \mathrm{m}^{2}$, being in the poor and middle household wealth quintiles.

Table 2. Odds Ratios and 95\% Confidence Intervals for Wasting among Children Under Five Years in Uganda.

\begin{tabular}{lll}
\hline \multirow{2}{*}{ Variables } & Wasting & $\mathbf{9 5 \%}$ Confidence Interval \\
\cline { 2 - 3 } & OR & \\
\hline Child`s Sex & & \\
Female & 1.00 & $0.50-1.32$ \\
Male & 0.82 & \\
\hline
\end{tabular}




\begin{tabular}{|c|c|c|}
\hline \multirow{2}{*}{ Variables } & \multicolumn{2}{|c|}{ Wasting } \\
\hline & OR & 95\% Confidence Interval \\
\hline \multicolumn{3}{|l|}{ Child`s age (Months) } \\
\hline $12-23$ & 1.00 & \\
\hline $6-11$ & 2.20 & $1.09-4.42$ \\
\hline $24-35$ & 0.26 & $0.07-0.97$ \\
\hline $36-47$ & 0.14 & $0.04-0.53$ \\
\hline $48-59$ & 0.22 & $0.05-0.94$ \\
\hline \multicolumn{3}{|l|}{ Child`s size at birth } \\
\hline Average & 1.00 & \\
\hline Very Small & 2.25 & $0.96-5.29$ \\
\hline Small & 1.95 & $0.91-4.18$ \\
\hline Large & 1.28 & $0.65-2.53$ \\
\hline Very Large & 1.04 & $0.34-3.12$ \\
\hline \multicolumn{3}{|c|}{ Infectious Disease last 2 weeks } \\
\hline No & 1.00 & \\
\hline Yes & 1.03 & $0.56-1.91$ \\
\hline \multicolumn{3}{|c|}{ Child`s Vaccination status } \\
\hline Fully vaccinated & 1.00 & \\
\hline Not fully vaccinated & 1.01 & $0.43-2.37$ \\
\hline \multicolumn{3}{|l|}{ Maternal Height (cm) } \\
\hline$<150$ & 0.99 & $0.37-2.63$ \\
\hline $150-154.9$ & 0.56 & $0.24-1.32$ \\
\hline $155-159.9$ & 1.06 & $0.56-2.03$ \\
\hline $160 \&$ above & 1.00 & \\
\hline \multicolumn{3}{|l|}{ Maternal BMI $\left(\mathrm{kg} / \mathrm{m}^{2}\right)$} \\
\hline $18.5-24.99$ & 1.00 & \\
\hline$<18.5$ & 3.39 & $1.72-6.70$ \\
\hline $25.0-29.99$ & 0.49 & $0.17-1.44$ \\
\hline $30 \&$ above & 2.17 & $0.59-8.03$ \\
\hline \multicolumn{3}{|c|}{ Maternal Formal Education level } \\
\hline Secondary/Tertiary & 1.00 & \\
\hline Not educated & 3.66 & $1.22-11.01$ \\
\hline Primary & 1.80 & $1.73-4.44$ \\
\hline \multicolumn{3}{|l|}{ Household sanitation } \\
\hline Improved & 1.00 & \\
\hline Unimproved & 1.26 & $0.72-2.21$ \\
\hline \multicolumn{3}{|c|}{ Sources of drinking water } \\
\hline Improved & 1.00 & \\
\hline Unimproved & 1.23 & $0.58-2.21$ \\
\hline \multicolumn{3}{|l|}{ Dietary Diversity score } \\
\hline Quintile 1(Lowest) & 1.88 & $0.64-5.50$ \\
\hline Quintile 2 & 0.81 & $0.28-2.29$ \\
\hline Quintile 3 & 1.71 & $0.56-5.26$ \\
\hline Quintile 4 & 1.30 & $0.43-3.95$ \\
\hline Quintile 5 (highest) & 1.00 & \\
\hline \multicolumn{3}{|l|}{ Wealth Index } \\
\hline Poorest & 0.82 & $0.27-2.47$ \\
\hline Poorer & 1.62 & $0.60-4.39$ \\
\hline Middle & 1.82 & $0.73-4.56$ \\
\hline Richer & 0.88 & $0.31-2.54$ \\
\hline Richest & 1.00 & \\
\hline
\end{tabular}

\subsection{Association between Risk Factors and Stunting}

As shown in Table 3, children in the age group of 24-35 months had increased risk of stunting than those aged 12-23 months, OR $(1.95 ; 1.17-3.23)$. Children with very small and small size at birth had $59 \%$ and $53 \%$ increased risk of stunting compared to those reported to have had average size at birth respectively. Maternal height of $<150 \mathrm{~cm}, 150-154 \mathrm{~cm}$, $155-159.9 \mathrm{~cm}$ were associated with $53 \%, 72 \%, 91 \%$ increase in stunting when compared to children whose maternal heights were $\geq 160 \mathrm{~cm}$. Lastly lack of maternal formal education was associated with $47 \%$ increase in stunting compared to children whose mothers had secondary or higher level of education and the reverse was true with maternal BMI $\geq 30$ which showed a $64 \%$ decrease in the risk of stunting in comparison with children whose mothers had normal body mass index. Other risk factors such as episode of infectious disease in the last two weeks preceding the survey, incomplete vaccination status, unimproved household sanitation, use of unimproved drinking water sources, low child dietary diversity score and poor household wealth status did not demonstrate statistically significant associations with childhood stunting. 
Table 3. Odds Ratios and 95\% Confidence Intervals for Stunting Among Children under five Years.

\begin{tabular}{|c|c|c|}
\hline \multirow{2}{*}{ Variables } & \multicolumn{2}{|c|}{ Stunting } \\
\hline & OR & 95\% Confidence Interval \\
\hline \multicolumn{3}{|l|}{ Child`s Sex } \\
\hline Female & 1.00 & \\
\hline Male & 1.56 & $1.12-2.18$ \\
\hline \multicolumn{3}{|l|}{ Child`s age (Months) } \\
\hline $12-23$ & 1.00 & \\
\hline $6-11$ & 0.26 & $0.16-0.41$ \\
\hline $24-35$ & 1.95 & $1.17-3.23$ \\
\hline $36-47$ & 1.02 & $0.69-1.51$ \\
\hline $48-59$ & 1.03 & $0.64-1.66$ \\
\hline \multicolumn{3}{|l|}{ Child`s size at birth } \\
\hline Average & 1.00 & \\
\hline Very Small & 2.59 & $1.58-4.27$ \\
\hline Small & 1.53 & $1.00-2.35$ \\
\hline Large & 0.94 & $0.65-1.36$ \\
\hline Very Large & 0.79 & $0.44-1.35$ \\
\hline \multicolumn{3}{|c|}{ Infectious Disease last 2 weeks } \\
\hline No & 1.00 & \\
\hline Yes & 1.33 & $0.93-1.88$ \\
\hline \multicolumn{3}{|c|}{ Child's Vaccination status } \\
\hline Fully vaccinated & 1.00 & \\
\hline Not fully vaccinated & 1.14 & $0.61-2.12$ \\
\hline \multicolumn{3}{|l|}{ Maternal Height (cm) } \\
\hline$<150$ & 7.53 & $4.07-13.94$ \\
\hline $150-154.9$ & 1.72 & $1.16-2.55$ \\
\hline $155-159.9$ & 1.91 & $1.37-2.66$ \\
\hline $160 \&$ above & 1.00 & \\
\hline \multicolumn{3}{|l|}{ Maternal BMI $\left(\mathrm{kg} / \mathrm{m}^{2}\right)$} \\
\hline $18.5-24.99$ & 1.00 & \\
\hline$<18.5$ & 0.76 & $0.49-1.18$ \\
\hline $25.0-29.99$ & 0.93 & $0.56-1.55$ \\
\hline $30 \&$ above & 0.36 & $0.14-0.92$ \\
\hline \multicolumn{3}{|c|}{ Maternal Formal Education level } \\
\hline Secondary/Tertiary & 1.00 & \\
\hline Not educated & 2.47 & $1.37-4.44$ \\
\hline Primary & 1.23 & $0.75-2.01$ \\
\hline \multicolumn{3}{|l|}{ Household sanitation } \\
\hline Improved & 1.00 & \\
\hline Unimproved & 0.92 & $0.67-1.24$ \\
\hline \multicolumn{3}{|c|}{ Sources of drinking water } \\
\hline Improved & 1.00 & \\
\hline Unimproved & 1.11 & $0.80-1.53$ \\
\hline \multicolumn{3}{|c|}{ Dietary Diversity score } \\
\hline Quintile 1(Lowest) & 0.99 & $0.59-1.70$ \\
\hline Quintile 2 & 1.37 & $0.88-2.14$ \\
\hline Quintile 3 & 1.66 & $0.90-2.79$ \\
\hline Quintile 4 & 1.25 & $0.67-1.83$ \\
\hline Quintile 5 (highest) & 1.00 & \\
\hline \multicolumn{3}{|l|}{ Wealth Index } \\
\hline Poorest & 1.04 & $0.53-2.07$ \\
\hline Poorer & 0.48 & $0.48-1.83$ \\
\hline Middle & 1.95 & $0.97-3.89$ \\
\hline Richer & 1.16 & $0.61-2.22$ \\
\hline Richest & 1.00 & \\
\hline
\end{tabular}

\section{Discussion}

Our results revealed five risk factors associated with childhood undernutrition in Uganda. These include; child`s small size at birth as a proxy measure of low birth weight, lack of or limited maternal formal education, low maternal body mass index (underweight), short maternal height stature and child's age range between 6-11 months. Of these risk factors, lack of maternal formal education, maternal underweight, child's age in the range of 6-11 months were associated with increased risk of wasting. Lack of maternal formal education tripled the risk of wasting among children aged 6-59 months in comparison to those whose mothers had a minimum of secondary education level or higher. This finding is consistent with the results of previous studies in 
developing countries, both in terms of its effect size and variability [2] suggesting the importance of maternal formal education in influencing household income and the influence of the later on household material resources [39] let alone maternal health knowledge which is equally essential for recommended child care practices and utilisation of available nutrition and healthcare services [40-42]. The second risk factor associated with wasting is maternal underweight. Low maternal body mass index $\left(<18.5 \mathrm{~kg} / \mathrm{m}^{2}\right)$ tripled the risk of wasting in children aged $<5$ years compared to children whose mothers had normal body mass index classification. This finding is also consistent with results from a study conducted by Corsi et al in India [43] and several others in developing countries [6], perhaps due to the link between maternal undernutrition and low birth weight [44] in newborns as well as the possibility of reduced maternal lactation and micronutrients in breast milk [45]. Another possible explanation for the association between maternal underweight and the increased risk of wasting in children could be the possibility that mothers who were undernourished were of low socio-economic status [44], an upstream factor which might have aggravated the impact of the other downstream risk factors on children's nutritional status. Lastly, younger children aged 6-11months had twofold increase in the risk of wasting when compared to those aged 12-23 months. This findings is also consistent with those from studies conducted in developing countries [6] and directly points to the critical period in which children transit from exclusive breastfeeding to complementary foods [46], hence probable contribution of infections and sub-optimal complementary feeding practices [47].

Regarding childhood stunting, children who had very small size at birth were twice more likely be stunted than average sized children at birth. It is not surprising as such and might be linked to the known relationship between maternal underweight and intrauterine growth restriction, the time point of clinical onset of stunting in children [48, 49]. The second risk factor associated with stunting among children $<$ 5 years of age was lack of maternal formal education. Our results indicated that children born to mothers with no formal education were twice more likely be stunted compared to those whose mothers had secondary school level education or more. This is not inconsistent with the results of previous studies $[2,50]$ and underpins the importance of maternal formal education as key upstream determinant of child health and health knowledge repository needed to safe-guard against potential health hazards and promote health seeking behaviour for improved child survival [51]. We also found that stunting in children $<5$ years tended to increase with decrease in maternal height, with the highest effect observed in children whose mothers had height of $<150 \mathrm{~cm}$ (7-fold increase) in comparison to children whose maternal heights were $\geq 160 \mathrm{~cm}$. This finding is in agreement with those from a meta-analysis conducted by Özaltin, Hill [52] in which they suggested possibility of intergenerational effects of malnutrition [49] given that maternal height might be reflection of her own childhood linear growth retardation
[53] that could be linked to familial socio-economic conditions and other causes of childhood malnutrition. On the flip side, our results showed protective effect of maternal underweight $\left(18.5 \mathrm{~kg} / \mathrm{m}^{2}\right)$ and obesity $\left(B M I \geq 30 \mathrm{~kg} / \mathrm{m}^{2}\right)$ against stunting. The later corroborates with results of similar analysis of demographic and health surveys data in developing countries [54]. This could perhaps be an indicator of increased maternal lactation capacity [45] and increased probability of giving birth to normal or overweight weight babies with reduced susceptibility to neonatal morbidity [55]. However our finding on the protective effect of maternal underweight on childhood stunting does not agree with results from many previous studies [6]. Risk factors that showed relatively strong effect on stunting but did not achieve statistical significance were child's dietary diversity score, child's household wealth status, experience of infectious disease in the last two weeks preceding the survey, child's incomplete vaccination status and household's use of unimproved drinking water sources.

\section{Conclusion}

Risk factors associated with wasting among children under five years in Uganda were maternal formal education and child's age, while those associated with stunting included children`s gender, age, size at birth, maternal height and maternal formal education level. This finding suggests that interventions to reduce under-five stunting and wasting in Uganda may benefit from focusing on improvement of maternal nutritional status and formal education. Further research is required to determine regional disparities in the distribution of risk factors for wasting and stunting among children under five years if appropriate malnutrition prevention and control interventions are to be tailored to address disparities.

\section{Limitations and Strengths}

Although our study identified persisting risk factors for undernutrition among children under five years in Uganda, the results should be interpreted with some caution. First, these results provide a snap-shot of persisting risk factors for undernutrition among children under five years, causation cannot be implied, and however the assessed risk factors are established in previous studies. Second, the use of a questionnaire to determine most of the risk factors might have led to misclassification of the exposures with respect to the outcomes. Third, measurement errors in child anthropometry might have occurred, which could have probably biased the results however the 2011 UDHS survey team was trained prior to the conduct of the survey, hence we expected minimum if none anthropometric measurement errors. Fourth, the age of the survey data might be of concern in making practical use of the findings however we do not expect substantial reduction in the persisting risk factors for wasting and stunting within a short period of time given the development indicators for Uganda. Despite of the above weaknesses, this is the only 
study that we know provided nationally representative results on the persisting risk factors for wasting and stunting among children under five years in Uganda.

\section{Conflict of Interest}

We have no conflict of interest to declare.

\section{Acknowledgements}

We wish to acknowledge the DHS program for granting access to the dataset. In addition we acknowledge Victoria University-Uganda for the institutional support rendered for this work and Mr Joshua Wesana for his valuable comments.

\section{References}

[1] Haddad, L. J., et al., Global Nutrition Report 2015: Actions and accountability to advance nutrition and sustainable development. 2015: Intl Food Policy Res Inst.

[2] Black, R. E., et al., Maternal and child undernutrition: global and regional exposures and health consequences. The lancet, 2008. 371(9608): p. 243-260.

[3] Ruia, A., R. K. Gupta, and G. Bandyopadhyay, Implication of Malnutrition on Human Capital: Bridging the Inequality through Robust economic Policies. Indian Journal of Public Health Research \& Development, 2018. 9(1): p. 75-79.

[4] Group, U. W. W. B., Joint child malnutrition estimates: key findings of the 2017 edition. U. 2017.

[5] Group, U. W. W. B., Joint Child Malnutrition Estimates 2016 edition. 2016.

[6] Black, R. E., et al., Maternal and child undernutrition and overweight in low-income and middle-income countries. The lancet, 2013. 382(9890): p. 427-451.

[7] UBOS, I., Uganda demographic and health survey 2011. Kampala and Claverton: Uganda Bureau of Statistics and ICF International Inc, 2012.

[8] Africa, U. N. E. C. f., The cost of hunger in Uganda: implications on national development and prosperity. 2014.

[9] Bourke, C. D., J. A. Berkley, and A. J. Prendergast, Immune Dysfunction as a Cause and Consequence of Malnutrition. Trends in immunology, 2016. 37(6): p. 386-398.

[10] Victora, C. G., et al., Maternal and child undernutrition: consequences for adult health and human capital. The lancet, 2008. 371(9609): p. 340-357.

[11] Hallal, P., et al., Maternal and child undernutrition: consequences for adult health and human capital. 2015.

[12] Dewey, K. G. and K. Begum, Long-term consequences of stunting in early life. Maternal \& child nutrition, 2011. 7(s3): p. $5-18$.

[13] Bhutta, Z. A., et al., Evidence-based interventions for improvement of maternal and child nutrition: what can be done and at what cost? The Lancet, 2013. 382(9890): p. 452477.
[14] Pelletier, D. L., et al., The nutrition policy process: the role of strategic capacity in advancing national nutrition agendas. Food and Nutrition Bulletin, 2011. 32(2 supp12): p. S59-S69.

[15] Halleröd, B., et al., Bad governance and poor children: a comparative analysis of government efficiency and severe child deprivation in 68 low-and middle-income countries. World Development, 2013. 48: p. 19-31.

[16] Group, W. W., Use and interpretation of anthropometric indicators of nutritional status. Bulletin of the World Health Organization, 1986. 64(6): p. 929.

[17] De Onis, M. and M. Blössner, The World Health Organization global database on child growth and malnutrition: methodology and applications. International journal of epidemiology, 2003. 32(4): p. 518-526.

[18] Onis, M., WHO Child Growth Standards based on length/height, weight and age. Acta paediatrica, 2006. 95(S450): p. 76-85.

[19] Keller, W. and C. Fillmore, [Prevalence of protein-energy malnutrition]. World health statistics quarterly. Rapport trimestriel de statistiques sanitaires mondiales, 1983. 36(2): p. 129-67.

[20] Allen, L., Maternal micronutrient malnutrition: effects on breast milk and infant nutrition, and priorities for intervention. SCN news, 1994. 11: p. 21-24.

[21] Unicef, The state of the world's children. 1998. 1994: Unicef.

[22] WHO, Stunted Growth and Development. 2016.

[23] Wamani, H., et al., Predictors of poor anthropometric status among children under 2 years of age in rural Uganda. Public Health Nutrition, 2006. 9(03): p. 320-326.

[24] Kikafunda, J. and J. Tumwine, Diet and socio-economic factors and their association with the nutritional status of preschool children in a low income suburb of Kampala City, Uganda. East African medical journal, 2006. 83(10): p. 565574.

[25] Owor, M., J. Tumwine, and J. Kikafunda, Socio-economic risk factors for severe protein energy malnutrition among children in Mulago Hospital, Kampala. East African medical journal, 2000. 77(9).

[26] Habaasa, G., An investigation on factors associated with malnutrition among underfive children in Nakaseke and Nakasongola districts, Uganda. BMC pediatrics, 2015. 15(1): p. 1.

[27] MeasureDHS. Demographic and Health Surveys 2011 [cited 2016; Available from: http://dhsprogram.com/data/dataset/Uganda_StandardDHS_2011.cfm.

[28] Statistics, U. B. O., 2002 Uganda population and housing census: main report. 2005: Uganda Bureau of Statistics.

[29] UNICEF. Cuases of malnutrition. 1997; Available from: http://www.unicef.org/sowc98/fig5.htm.

[30] Mei, Z. and L. M. Grummer-Strawn, Standard deviation of anthropometric Z-scores as a data quality assessment tool using the 2006 WHO growth standards: a cross country analysis. Bulletin of the World Health Organization, 2007. 85(6): p. 441-448. 
[31] Corsi, D. J., M. A. Subramanyam, and S. Subramanian, Commentary: Measuring nutritional status of children. International journal of epidemiology, 2011. 40(4): p. 10301036.

[32] Bhutta, Z. A., et al., What works? Interventions for maternal and child undernutrition and survival. The Lancet, 2008. 371(9610): p. 417-440.

[33] Gove, S., Integrated management of childhood illness by outpatient health workers: technical basis and overview. The WHO Working Group on Guidelines for Integrated Management of the Sick Child. Bulletin of the World Health Organization, 1997. 75(Suppl 1): p. 7.

[34] Barros, A. J., et al., Equity in maternal, newborn, and child health interventions in Countdown to 2015: a retrospective review of survey data from 54 countries. The Lancet, 2012. 379(9822): p. 1225-1233.

[35] Romero-Corral, A., et al., Accuracy of body mass index in diagnosing obesity in the adult general population. International journal of obesity, 2008. 32(6): p. 959-966.

[36] WHO/UNICEF. Improved and unimproved water sources and sanitation facilities. 1991 [cited 2016 13/10/2016]; Available from: http://www.wssinfo.org/definitions-methods/watsancategories/.

[37] Rutstein, S. O., The DHS Wealth Index: Approaches for rural and urban areas. 2008.

[38] MeasureDHS. Demographic and Health Surveys 2013. 2016 [cited 2016 20/11/2016]; Available from: http://www.dhsprogram.com/Data/.

[39] Harding, J. F., Increases in maternal education and lowincome children's cognitive and behavioral outcomes. Developmental psychology, 2015. 51(5): p. 583.

[40] Ickes, S. B., T. E. Hurst, and V. L. Flax, Maternal literacy, facility birth, and education are positively associated with better infant and young child feeding practices and nutritional status among Ugandan children. The Journal of nutrition, 2015. 145(11): p. 2578-2586.

[41] Saleem, A. F., et al., Impact of maternal education about complementary feeding on their infants' nutritional outcomes in low-and middle-income households: a community-based randomized interventional study in Karachi, Pakistan. Journal of health, population, and nutrition, 2014. 32(4): p. 623.

[42] Imdad, A., M. Y. Yakoob, and Z. A. Bhutta, Impact of maternal education about complementary feeding and provision of complementary foods on child growth in developing countries. BMC Public Health, 2011. 11(3): p. 1.

[43] Corsi, D. J., I. Mejía-Guevara, and S. Subramanian, Risk factors for chronic undernutrition among children in India:
Estimating relative importance, population attributable risk and fractions. Social Science \& Medicine, 2015. 30: p. 1e21.

[44] Belkacemi, L., et al., Maternal undernutrition influences placental-fetal development. Biology of reproduction, 2010. 83(3): p. 325-331.

[45] Brown, K. H., et al., Lactational capacity of marginally nourished mothers: relationships between maternal nutritional status and quantity and proximate composition of milk. Pediatrics, 1986. 78(5): p. 909-919.

[46] Kramer, M. S. and R. Kakuma, SECTION II-SCIENCE AND POLICY: OPTIMAL DURATION OF EXCLUSIVE BREASTFEEDING-The Optimal Duration of Exclusive Breastfeeding: A Systematic Review. Advances in Experimental Medicine and Biology, 2004. 554: p. 63-78.

[47] Keusch, G. T., The history of nutrition: malnutrition, infection and immunity. The Journal of nutrition, 2003. 133(1): p. 336S340 S.

[48] Prendergast, A. J. and J. H. Humphrey, The stunting syndrome in developing countries. Paediatrics and international child health, 2014. 34(4): p. 250-265.

[49] Varela-Silva, M. I., et al., Influence of maternal stature, pregnancy age, and infant birth weight on growth during childhood in Yucatan, Mexico: a test of the intergenerational effects hypothesis. American Journal of Human Biology, 2009. 21(5): p. 657-663.

[50] Charmarbagwala, R., et al., The determinants of child health and nutrition: a meta-analysis. Washington, DC: World Bank, 2004.

[51] Ahmed, S., et al., Economic status, education and empowerment: implications for maternal health service utilization in developing countries. PloS one, 2010. 5(6): p. e11190.

[52] Özaltin, E., K. Hill, and S. Subramanian, Association of maternal stature with offspring mortality, underweight, and stunting in low-to middle-income countries. Jama, 2010. 303(15): p. 1507-1516.

[53] Martorell, R., Body size, adaptation and function. Human Organization, 1989. 48(1): p. 15-20.

[54] Hasan, M. T., et al., Long-term changes in childhood malnutrition are associated with long-term changes in maternal BMI: evidence from Bangladesh, 1996-2011. The American Journal of Clinical Nutrition, 2016. 104(4): p. 1121-1127.

[55] Abu-Saad, K. and D. Fraser, Maternal nutrition and birth outcomes. Epidemiologic reviews, 2010. 32(1): p. 5-25. 